\title{
CONFORMATION STUDIES ON AND ASSESSMENT BY SPECTRAL ANALYSIS OF THE PROTEIN-CHROMOPHORE INTERACTION OF THE MACROMOLECULAR ANTITUMOR ANTIBIOTIC C-1027
}

\author{
TOSHIO OTANI \\ Anticancer \& Antimicrobial Research Laboratory, Taiho Pharmaceutical Co. Ltd., \\ Kawauchi-cho, Tokushima 771-01, Japan
}

(Received for publication December 21, 1992)

\begin{abstract}
Characterization of the secondary structure of the antitumor antibiotic C-1027 has been made from a comparison of $\mathrm{C}-1027$ and its apoprotein by various analytical means. The results indicated the antibiotic to be abundant in $\beta$-structure by measurements of Fourier-transform infrared (FT-IR) spectroscopy and the circular dichroism (CD) spectrum, and by a prediction of the secondary structure based on the amino acid sequence of the peptide. In comparison of the IR spectra of their proteins in $\mathrm{D}_{2} \mathrm{O}$, the apoprotein exhibited a faster $\mathrm{H}-\mathrm{D}$ exchange than $\mathrm{C}-1027$, indicating an increase in the "non-motile parts" of the $\beta$-sheets formed through the protein-chromophore interaction in holo-C-1027. The prediction of hydropathic index indicated the hydrophobic residues of the apoprotein to be predominantly located in the $\beta$-sheet structures, suggesting hydrophobic interaction in the binding between chromophore and apoprotein. Further, the interaction between chromophore and apoprotein was detected by a fluorescence method. The result showed the dissociation constant $(\mathrm{Kd})$ to be $6.88 \times 10^{-5} \mathrm{M}$, indicating that the chromophore is tightly bound to the protein moiety.
\end{abstract}

The antitumor antibiotic C-1027 and its apoprotein, C-1027-AG, were isolated at the same time from a culture filtrate of Streptomyces globisporus C-1027. This antibiotic has been extensively characterized during recent years, and has been shown to be composed of an apoprotein and an associated non-protein chromophore ${ }^{1,2)}$. The apoprotein is an acidic single-chain polypeptide composed of 110 amino acid residues, M.W. ca. 10,500, whose primary structure has been recently elucidated on the basis of the Edman degradation procedure using fragment peptides obtained by enzyme hydrolysis ${ }^{3}$, and also from cloning and nucleotide sequencing of the apoprotein gene. ${ }^{4)}$ The sequence was determined as shown in Fig. 1. It notably lacks methionine and tryptophan residues in its composition and contains 2 intramolecular disulfide bonds, one between cys(36) and cys(45), and the other between cys(86) and cys(91). On the other hand, although the total chemical structure of the non-protein chromophore has not yet been elucidated because of exceptional instability, the chromophore extracted with ethyl acetate under alkaline conditions has been characterized, and the structure of one of its degradation products, component II- $\mathrm{F}_{3}$, has been reported to be 3,4-dihydro-7-methoxy-2-methylene-3-oxo-2H-1,4-benzoxazine-5-carboxylic

Fig. 1. Amino acid sequence of $\mathrm{C}-1027$ apoprotein.

Ala-Pro-Ala-Phe-Ser-Val-Ser-Pro-Ala-Ser-Gly-Leu-Ser-Asp-Gly-Gln-Ser-Val-Ser-Val-Ser-Val-Ser-Gly-Ala-

Ala-Ala-Gly-Glu-Thr-Tyr-Tyr-Ile-Ala-GIn-Cys-Ala-Pro-Val-Gly-Gly-GIn-Asp-Ala-Cys-Asn-Pro-Ala-Thr-

Ála-Thr-Ser-Phe-Thr-Thr-Asp-Ala-Ser-Gly-Ala-Ala-Ser-Phe-Ser-Phe-Val-Val-Arg-Lys-Ser-Tyr-Thr-Gly80

Ser-Thr-Pro-Glu-Gly-Thr-Pro-Val-Gly-Ser-Val-Asp-Cys-Ala-Thr-Ala-Ala-Cys-Asn-Leu-Gly-Ala-Gly-Asn-

Ser-Gly-Leu-Asp-Leu-Gly-His-Val-Ala-Leu-Thr-Phe-Gly 
acid $^{5)}$ (Fig. 2). Several biological properties of C-1027 have been described, such as growth inhibition of Gram-positive bacteria, of some strains of Gram-negative bacteria, and of a number of transplantable solid tumors and leukemias in mice ${ }^{6)}$. It has been shown that L-1210 cells grown in tissue culture in the presence of C-1027 undergo a preferential inhibition of DNA synthesis and that C-1027 treatment results in cleavage of cellular DNA in vitro and in vivo ${ }^{7,8)}$. All the biological activity of $\mathrm{C}-1027$ was reported to be associated with the non-protein chromophore that was extractable by organic solvents, while the apoprotein, C-1027-AG, did not show any antimicrobial and antitumor activities. Furthermore, we found that antibiotic C-1027 (holo-antibiotic) had some aminopeptidase activity but that neither its chromophore nor its apoprotein alone had any activity and that the cytotoxicity in vitro was diminished by amastatin, an inhibitor of aminopeptidase ${ }^{9}$.

C-1027 is one of a large group of protein antibiotics isolated from different strains of Streptomyces, and members of the group include neocarzinostatin $(\mathrm{NCS})^{10}$, auromomycin $(\mathrm{AUR})^{11)}$, macromomycin $(\mathrm{MCR})^{12)}$, largomycin $(\mathrm{LRG})^{13)}$, and actinoxanthin $(\mathrm{AXN})^{14)}$. NCS and other members of this family of antitumor agents are similar in size, and share amino acid sequence homology with C-1027. However, these antibiotics may be presumed to differ in the secondary and three-dimensional structure of the apoprotein and in the structure of this chromophore. In the present communication, we will discuss side chain conformations based on circular dichroism (CD) data, and peptide backbone conformation (secondary structure) based on infrared (IR) spectroscopy for C-1027 and its apoprotein to understand the features of the C-1027 non-protein chromophore environment. Further, the mode of binding between the apoprotein and non-protein chromophore is described based on the determination of fluorescence emission. We also make a prediction of the secondary structure and assign the hydropathic index of C-1027 by using a computer program developed for this purpose, and compare our results with those on other protein antibiotics.

\section{Materials and Methods}

\section{Chemicals}

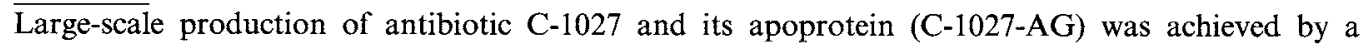
purification procedure, employing DEAE-cellulofine, Butyl-cellulofine, and Cellulofine GCL-90 (Seikagaku Kogyo Co., Ltd.), that represents an improvement over the previously described process ${ }^{3)}$. The purified C-1027 exhibited an absorption maximum at $275 \mathrm{~nm}$ and a broad shoulder between 340 and $360 \mathrm{~nm}$. In the spectrum of the apoprotein, the 275-nm peak was observed, but the broad shoulder was absent. C-1027-UV was prepared by lyophilization after irradiation with UV-light for 1 hour, as reported in our previous paper $^{2)}$. The hydrochloride salt of chromophore component II (chr-II) was obtained by preparative high-pressure liquid chromatography (HPLC) on a TSKgel ODS-120A column $(30 \times 10.8 \mathrm{~cm}, \mathrm{i} . \mathrm{d}$., Tosoh Co., Ltd.), with acetonitrile $-0.01 \mathrm{~N} \mathrm{HCl}(25: 75)$ as eluant, of an ethyl acetate extract of the crude protein as described previously ${ }^{5}$. In all steps, care was taken to reduce the exposure of the drug to light. All the other chemicals used were of the highest grade commercially available.

Spectral Studies

The CD spectra were measured under identical experimental conditions under a constant nitrogen flush with a JASCO J-500A spectropolarimeter equipped with a data processor. CD spectra were recorded 
in the wavelength region of $200 \sim 450 \mathrm{~nm}$ in $1 / 15 \mathrm{M}$ phosphate buffer (pH 7.0) for $\mathrm{C}-1027$ and apoprotein and in $\mathrm{MeOH}$ solution for chr-II. The observations were expressed in terms of $\Delta \varepsilon$ in $\mathrm{cm}^{-1} \cdot \mathrm{mol}^{-1}$.

Fourier-transform infrared (FT-IR) measurements were performed at room temperature with a JEOL JIR-100 spectrometer. The respective spectra of C-1027, its apoprotein, and C-1027-UV $(1.5 \mathrm{mg} / 200 \mu \mathrm{l})$ were measured at $4 \mathrm{~cm}^{-1}$ resolution from 1300 to $1800 \mathrm{~cm}^{-1}$ in duterium oxide $\left(D_{2} \mathrm{O}\right)$ solution, and signals of 200 scans were averaged. The H-D exchanges were measured at 5, 30, and 120 minutes after addition of $\mathrm{D}_{2} \mathrm{O}$. The deconvolved spectra for the prediction of secondary structure were resolved in Gaussian components from 1600 to $1700 \mathrm{~cm}^{-1}$ at 5 minutes after addition of $\mathrm{D}_{2} \mathrm{O}$ by the curve-fitting analysis of a computer program that utilizes Gaussian-Newton interaction.

Fluorescence studies were performed on a Hitachi 650-40 spectrofluorometer. C-1027 and its apoprotein were usually analyzed at a concentration of $0.5 \mathrm{mg} / \mathrm{ml}$ in $0.01 \mathrm{M}$ Tris-HCl buffer solution ( $\mathrm{pH} 7.9$ ). Emission spectra were recorded at excitation wavelengths of 280 and $350 \mathrm{~nm}$. Spectra were taken at $10^{\circ} \mathrm{C}$-intervals ranging from 30 to $80^{\circ} \mathrm{C}$ with the temperature controlled by a thermoregulator. To test the interaction between apoprotein and non-protein chromophore, we prepared C-1027 chr-II (from 0.8 to $\left.5 \times 10^{-5} \mathrm{M}\right)$ and apoprotein $\left(5 \times 10^{-5} \mathrm{M}\right)$ solutions in the same buffer. Kinetic measurements of fluorescence change were conducted by adding buffer solution containing apoprotein to chr-II in aqueous buffer solutions, and changes in the 426-nm fluorescence of chr-II excited at $350 \mathrm{~nm}$ were observed. Kinetic constant was determined from the linear correlation between $1 / \Delta \mathrm{F}$ and $1 /(\mathrm{C})$ according to the method of KONDO et al. ${ }^{15)}$.

\section{Results and Discussion}

Fig. 3 shows CD spectra of $\mathrm{C}-1027$ and apoprotein in $1 / 15 \mathrm{M}$ phosphate buffer (pH 7.0) in comparison with that of C-1027 chr-II. Their CD spectra were essentially identical in the region of the peptide absorbance ( $210 \sim 245 \mathrm{~nm}$ ), but differed at the longer wavelengths. C-1027 showed a negative peak centered around 300 and $350 \mathrm{~nm}$ attributed to the non-protein chromophore that was absent in the apoprotein. Both proteins, having two disulfide bonds, contain the following chromophores, which might contribute to the

Fig. 3. CD spectra of C-1027, apoprotein, and chromophore component II.

- C-1027, --- apoprotein, - - - chromophore component II.

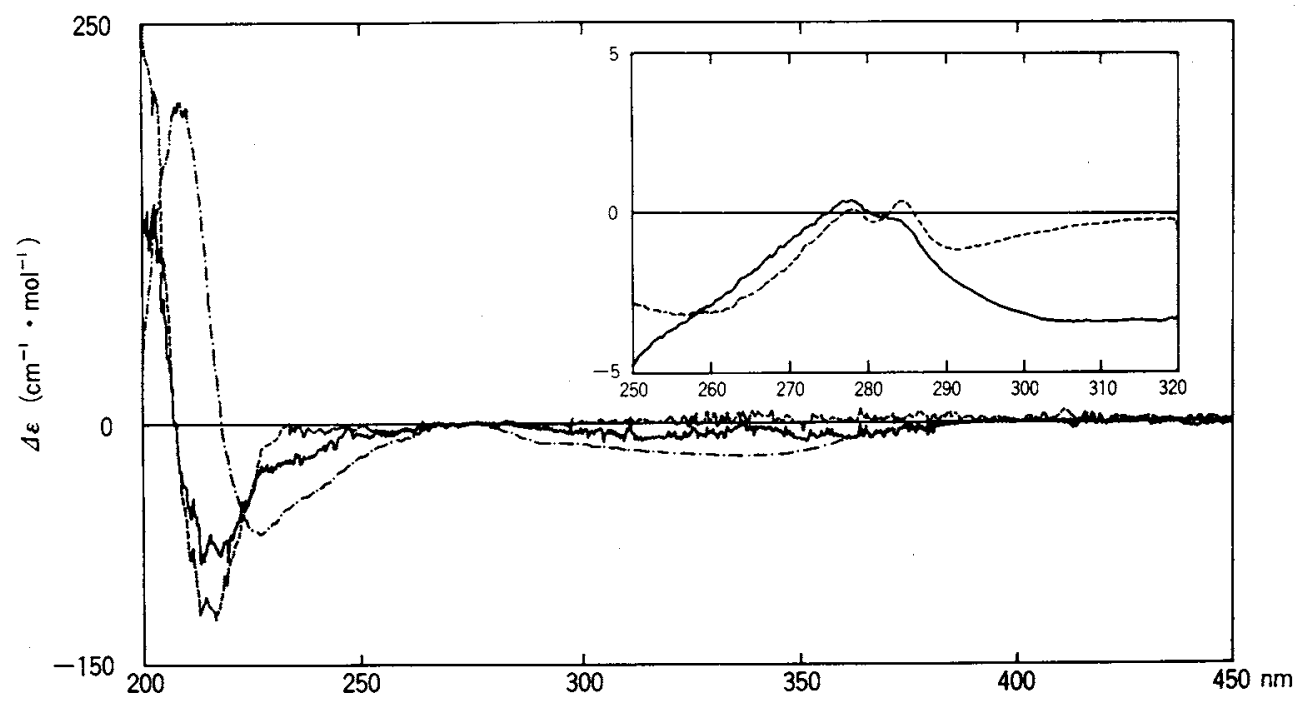

The respective spectra from 200 to $450 \mathrm{~nm}$ were taken of a $0.2 \mathrm{mg} / \mathrm{ml}$ solution in a cell of $1-\mathrm{mm}$ path length. The spectra from 250 to $320 \mathrm{~nm}$ (inset) were of a $1.0 \mathrm{mg} / \mathrm{ml}$ solution in a cell of $10-\mathrm{mm}$ path length. 
Fig. 4. Changes in CD spectra of antibiotic C-1027 (a) and apoprotein (b).

The first spectrum was obtained at $30^{\circ} \mathrm{C}-$, followed by spectra at $40^{\circ} \mathrm{C}---, 50^{\circ} \mathrm{C}---, 60^{\circ} \mathrm{C}$ ,$--- 70^{\circ} \mathrm{C}---, 80^{\circ} \mathrm{C}-$ and $90^{\circ} \mathrm{C}--\ldots$.
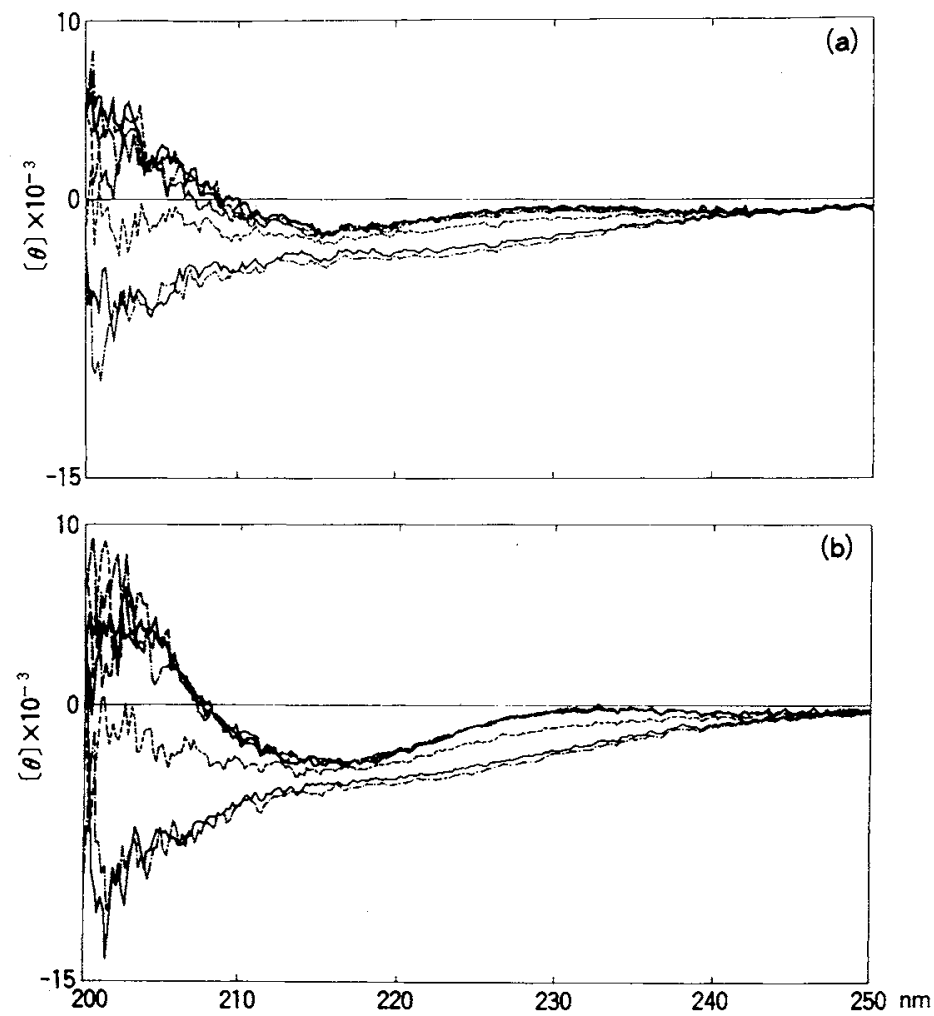

C-1027 and apoprotein $(0.4 \mathrm{mg} / \mathrm{ml})$ in $1 / 15 \mathrm{M}$ phosphate buffer $(\mathrm{pH} 7.0)$ were heated by $10^{\circ} \mathrm{C}$ increments to $90^{\circ} \mathrm{C}$.

$\mathrm{CD}$ measurement: three tyrosines and five phenylalanines. The positive extremum at $203 \mathrm{~nm}$ and the negative one at $219 \mathrm{~nm}$, indicative of a large percentage of $\beta$-pleated sheet structure, are consistent with a tightly folded native configuration, though the ellipticities shown were lower than those of the $\beta$-pleated sheet. Several attempts have been made to predict protein conformation from amino acid sequence and amino acid composition by use of proteins of known conformation. Using parameters published by YANG et al. ${ }^{16)}$, we attempted to calculate the contributions of $\alpha$-helical, $\beta$-pleated, and randomly coiled segments toward the conformation of $\mathrm{C}-1027$ and its apoprotein. The respective structure contents calculated as compared with those of ordinary proteins such as globulin were as follows: $\alpha$-helix, $-2 \%,-7 \%$; $\beta$-sheet, $39 \%, 59 \% ; \beta$-turn, $5 \%,-12 \%$; random coil, $59 \%, 60 \%$. As CD is a very useful method for detecting conformational changes in proteins, we examined the effect of temperature on the secondary structure of C-1027 and of its apoprotein by measuring their CD spectra. As shown in Fig. 4, the positive band at around $203 \mathrm{~nm}$ was transformed with increasing temperature to a negative band at the boundary ranging near $70^{\circ} \mathrm{C}$, while the negative band at around $216 \mathrm{~nm}$ was scarcely influenced in either protein. These spectral changes of both proteins suggest that the content of $\beta$-sheet structure decreased. However, the usefulness of these data for obtaining specific information about the peptide backbone remains uncertain. 
Fig. 5. Changes in IR spectra of C-1027, apoprotein, and C-1027-UV in amide I and II regions after $\mathrm{D}_{2} \mathrm{O}$ addition.

- 5 minutes after $\mathrm{D}_{2} \mathrm{O}$ addition, ---: 30 minutes, $----: 120$ minutes.
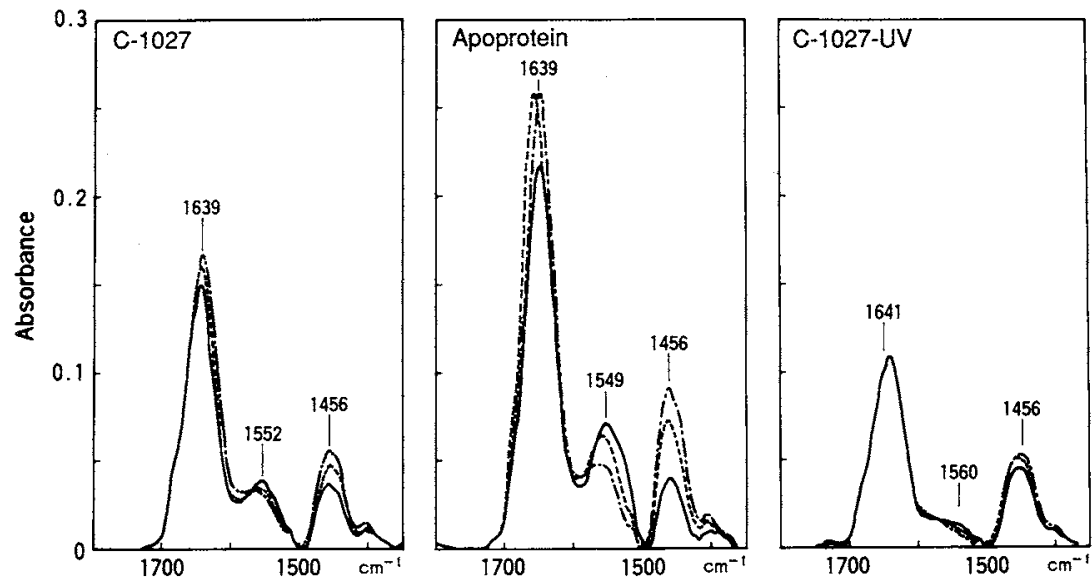

C-1027-UV: C-1027 was irradiated with UV-light for 1 hour from a distance of $25 \mathrm{~cm}$.

Fig. 6. FT-IR spectra of C-1027 (a) and apoprotein (b) and resolution into Gaussian bands.

- Amide I band found, --- Gaussian bands.

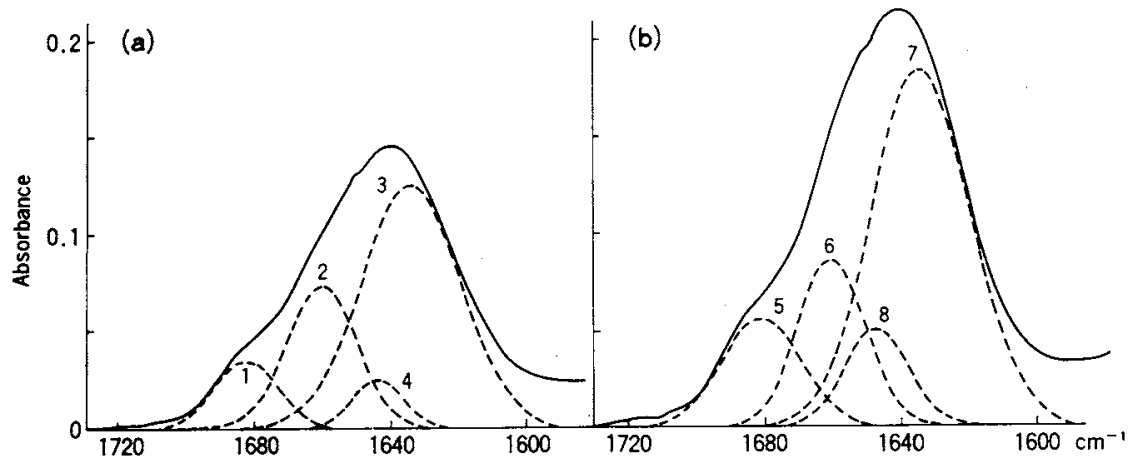

The symbois 1 and 5, 2 and 6,3 and 7, and 4 and 8 indicate $\beta$-turn, $\alpha$-helix, $\beta$-sheet and other, respectively.

Band assignments in IR spectroscopy are primarily based on the mode of vibrations attributed to $\mathrm{C}=\mathrm{O}$ stretching (amide $\mathrm{I}, 1650 \mathrm{~cm}^{-1}$ region) and $\mathrm{NH}$ deformation (amide II, $1530 \mathrm{~cm}^{-1}$ region), thus avoiding the perturbation caused by other side chain chromophores that usually have small and different absorption bonds of predictable area. C-1027 and its apoprotein showed similar IR spectra in amide I and II regions in $\mathrm{D}_{2} \mathrm{O}$ solution (Fig. 5). The spectral characteristics obtained here, as a strong absorption for amide I around $1639 \mathrm{~cm}^{-1}$ and a weaker one close to $1684 \mathrm{~cm}^{-1}$, and as an intense amide II frequency at $1552 \mathrm{~cm}^{-1}$, are similar to those in the literature for antiparallel $\beta$-pleated sheet proteins ${ }^{17)}$. The absorption at $1651 \mathrm{~cm}^{-1}$ indicates $\alpha$-helix conformation. The amide II absorption around $1552 \mathrm{~cm}^{-1}$ occurred at a longer wavelength in comparison with that of $\mathrm{NCS}^{18,19)}, \mathrm{MCR}, \mathrm{AUR}{ }^{20)}$ and their apoproteins. We resolved the IR spectra of the amide I region corresponding to each of the four secondary structures based on the method reported by SARVER ${ }^{21)}$. Fig. 6 shows the calculated amide I region at the peak 
Table 1. Analysis of secondary structures by individual component bands of amide I band with C-1027 and apoprotein.

\begin{tabular}{lcccc}
\hline & $\begin{array}{c}\text { Peak } \\
\text { No. }^{2}\end{array}$ & $\begin{array}{c}\text { Wave- } \\
\text { length } \\
\left(\mathrm{cm}^{-1}\right)\end{array}$ & $\begin{array}{c}\text { Absorb- } \\
\text { ance }^{\mathrm{b}}\end{array}$ & $\%^{\mathrm{c}}$ \\
\hline C-1027 & 1 & 1682 & 0.036 & 14 \\
& 2 & 1660 & 0.074 & 28 \\
& 3 & 1634 & 0.125 & 48 \\
Apoprotein & 4 & 1644 & 0.026 & 10 \\
& 5 & 1681 & 0.056 & 15 \\
& 6 & 1660 & 0.086 & 23 \\
& 7 & 1633 & 0.184 & 49 \\
& 8 & 1647 & 0.050 & 13 \\
\hline
\end{tabular}

a Peak numbers were correlated with respective secondary structures, as shown in Fig. 6.

b Absorbance as integrated intensities.

- Percent of total absorbance.

positions of $1682,1660,1644$, and $1634 \mathrm{~cm}^{-1}$ for the $\beta$-turn, $\alpha$-helix, others, and $\beta$-sheet conformation, respectively. The positions of these bands are
Fig. 7. Time course of H-D exchange in C-1027, apoprotein, and C-1027-UV.

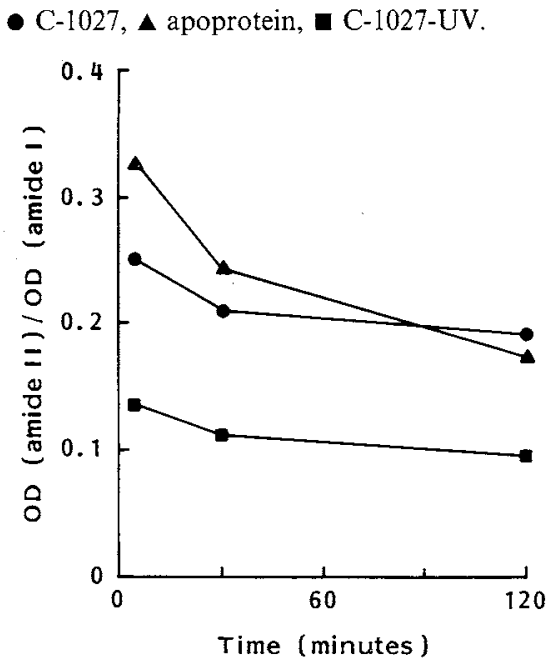

C-1027-UV: C-1027 was irradiated with UV-light for 1 hour from a distance of $25 \mathrm{~cm}$.

given in Table 1 along with their absorption intensities, which are related to the population of the corresponding secondary structure. The results suggest the presence of approximately $50 \% \beta$-structure in both $\mathrm{C}-1027$ and its apoprotein. This result is compatible with the amino acid compositions of both proteins. These proteins have many threonine (10 residues/110 residue), valine (10/110), glycine (15/110), and proline (6/110) residues, which make up approximately $40 \%$ of the total amino acids, and they preferentially compose the $\beta$-sheet as shown in NCS, AUR, and MCR. Glycine (15/110), which destabilizes $\alpha$-helix structure ${ }^{22)}$, is present as the most abundant amino acid in this protein.

After addition of $\mathrm{D}_{2} \mathrm{O}$ to lyophilized $\mathrm{C}-1027$, apoprotein, and C-1027-UV, the decrease in the ratio of amide II to amide I absorbance in the proportion of $\mathrm{H}$-D exchange was faster in the apoprotein than in $\mathrm{C}-1027$ (Fig. 7). $\mathrm{H}-\mathrm{D}$ exchange velocity in the $\mathrm{NH}-\mathrm{CO}$ of apoprotein is greater than that in $\mathrm{C}-1027$. These results show holo-C-1027 and apoprotein to be similar in IR spectra in a static configuration, but different in the H-D exchange, thus reflecting a dynamic configuration freedom denoted by "motility", as was also noted in AUR and $\mathrm{MCR}^{20)}$. This difference among these proteins is relative to the difference in their chromophore. Therefore, these data presumably indicate the existence of "non-motile parts" of the $\beta$-sheet formed through the apoprotein-chromophore interaction in C-1027. On the other hand, the H-D exchange of UV-irradiated C-1027 was similar to that of holo-C-1027. We reported previously that the enzymatic and antitumor activities of the holo-antibiotic were readily lost upon UV-irradiation, indicating that the intact structure of the chromophore was needed to maintain the native conformation of the holo-antibiotic ${ }^{9}$. Thus, the conformation of the apoprotein may be very important for binding of the C-1027 chromophore. Such properties of the apoprotein should be important in connection with stability of the C-1027 chromophore and its biological activities.

Based on the complete amino acid sequence determined in the previous study ${ }^{3,4)}$, we attempted by the method of CHOU and FASMAN ${ }^{22)}$ to predict the secondary structure of this protein using computer program developed for this purpose. As shown in Fig. 8, we propose two helical segments, five $\beta$-sheet regions, and 
Fig. 8. Prediction of secondary structure of C-1027 apopretein.
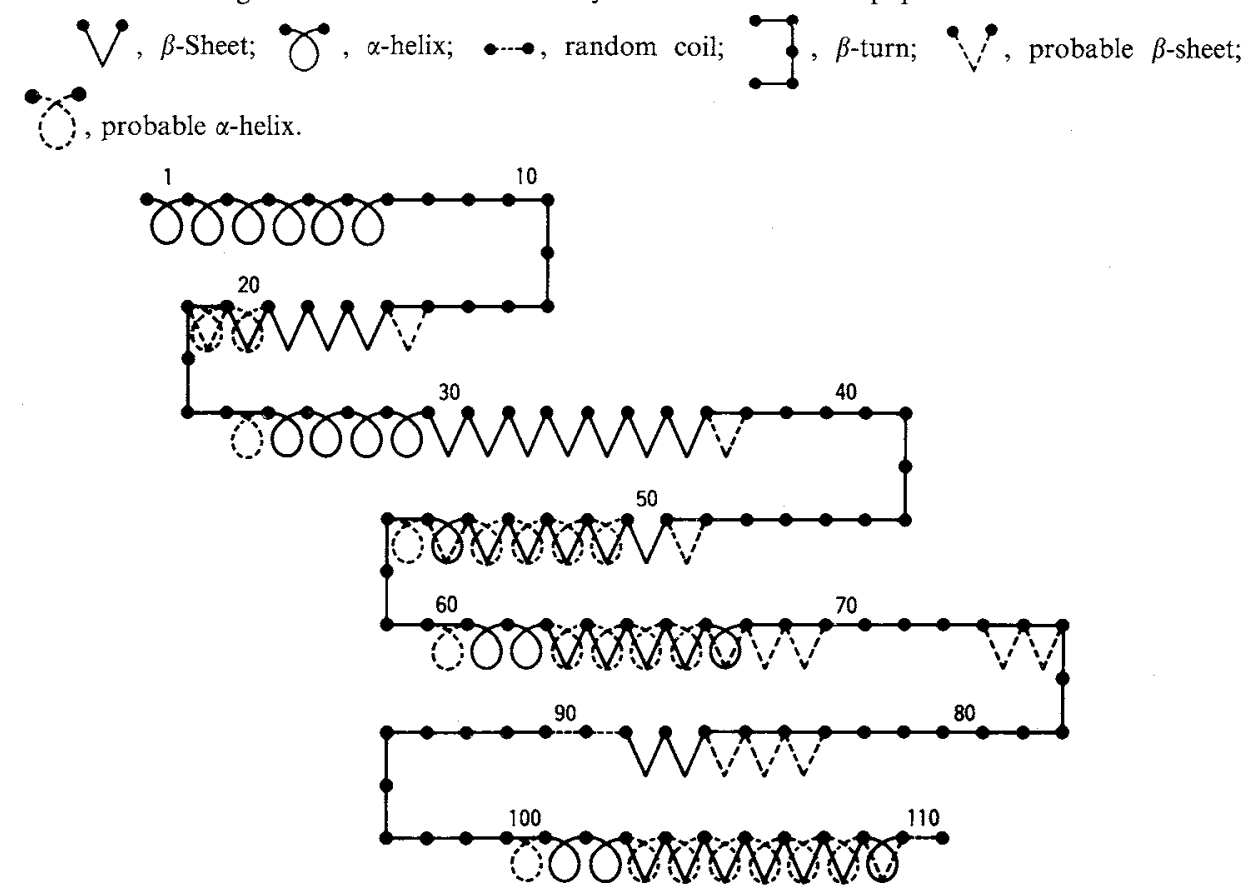

The prediction was made by the method of CHOU and FASMAN ${ }^{22)}$, using a computer program.

six $\beta$-turns. The coil form was assigned to the remaining segments. The fraction of the total residues represented by each form was $15 \%$ by helices, $26 \%$ by $\beta$-sheets, $56 \%$ by $\beta$-turns, and $3 \%$ by random coils. However, $\alpha$-helix and $\beta$-turn regions at $16 \sim 17,21 \sim 22,37 \sim 38,49 \sim 50,55 \sim 56,67 \sim 70,74 \sim 76$, $84 \sim 87$, and $108 \sim 109$ may possibly exist as $\beta$-sheet. If true, the percentage of each form among the total residues would be $13 \%$ for $\alpha$-helices, $38 \%$ for $\beta$-sheets, $46 \%$ for $\beta$-turns, and $3 \%$ for random coils. This result resembles closely that obtained by CD or IR analysis. These findings suggest that $\mathrm{C}-1027$ and its apoprotein are rather poor in $\alpha$-helix type structure. This result is in agreement with the fact that the amino acid composition is more in favor of a "non-helix" type structure. These observations indicate that C-1027 possesses a very tightly folded conformation, which probably is due to the considerable content of $\beta$-pleated sheet structure.

Hydrophilic-hydrophobic properties of $\mathrm{C}-1027$ apoprotein were examined by means of the hydropathic index plot of KYTE and DoolitTLE ${ }^{23}$. As shown in Fig. 9 with the single-letter designation of amino acid sequence, there are mainly five hydrophobic regions in the apoprotein, located in positions $17 \sim 22,32 \sim 36$, $60 \sim 64,79 \sim 86$, and $100 \sim 107$. Hydrophobic residues of the apoprotein are predominantly located in the $\beta$-sheet structure. In the case of NCS the highly hydrophobic clusters in the apoprotein are necessary for binding of the latter to its chromophore ${ }^{24)}$. Likewise, these five hydrophobic clusters in the apoprotein of C-1027 may play an important role in the hydrophobic interaction with the hydrophobic part of its non-protein chromophore. In practice, separation of the apoprotein from $\mathrm{C}-1027$ may be achieved by taking advantage of the difference in hydrophobicity by the purification of $\mathrm{C}-1027$ on Butylcellulofine.

Fluorescence spectra of $\mathrm{C}-1027$ and its apoprotein in $0.01 \mathrm{M}$ Tris- $\mathrm{HCl}$ buffer $(\mathrm{pH} 7.9$ ) were as shown in Fig. 10 with the fluorescence excitation spectrum monitored at 280 and $350 \mathrm{~nm}$. The fluorescence emission 
Fig. 9. Plot of hydropathic index of C-1027. (1) Hydrophobic amino acid; (2) hydrophilic amino acid.

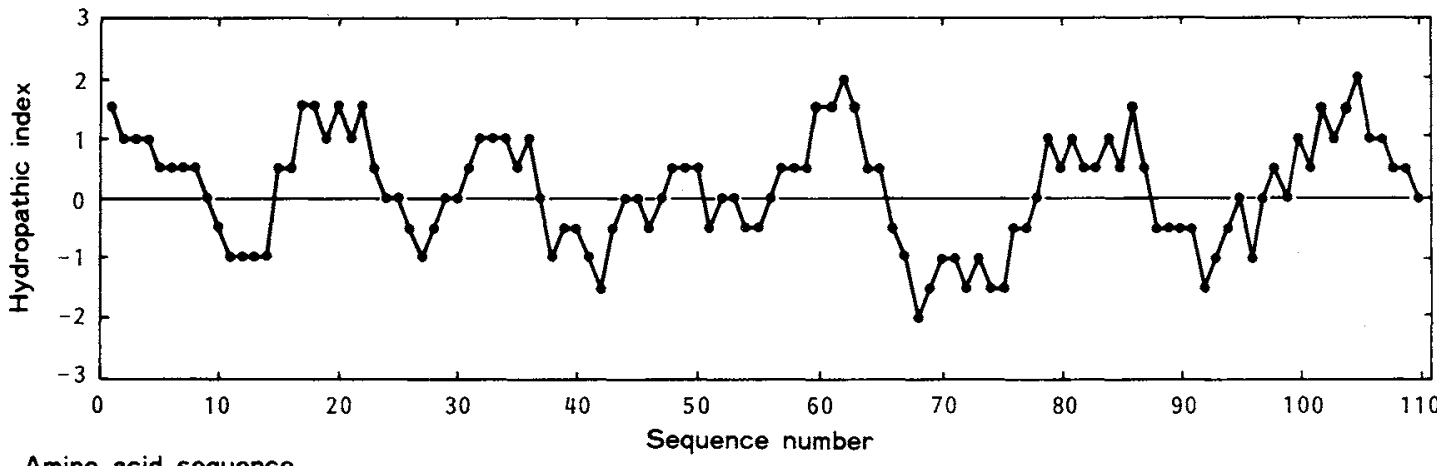

Amino acid sequence

(1) APAFSVSPA GQSVSVSVSGA YYIAQCA AC ATA DASGAASFSF

(2)

SGLSD

AAGET

PVGGQD NP TSFTT

VVRKSYTGSTPE

GTPVGSVDCA

A SGLDLGHVALTF

The hydropathic indices were calculated over every 9 residues by the method of KYTE and DOOLITTLE ${ }^{23 !}$

Fig. 10. Thermal denaturation fluorescence emission spectra of C-1027 apoprotein (a) and C-1027 (b).

The first spectrum was obtained at $30^{\circ} \mathrm{C} \longrightarrow$, followed by spectra at $40^{\circ} \mathrm{C}---, 50^{\circ} \mathrm{C}---$ $60^{\circ} \mathrm{C}-\cdots-70^{\circ} \mathrm{C}---$, and $80^{\circ} \mathrm{C}-$. Left panels, excitation at $280 \mathrm{~nm}$; right panels, excitation at $350 \mathrm{~nm}$.

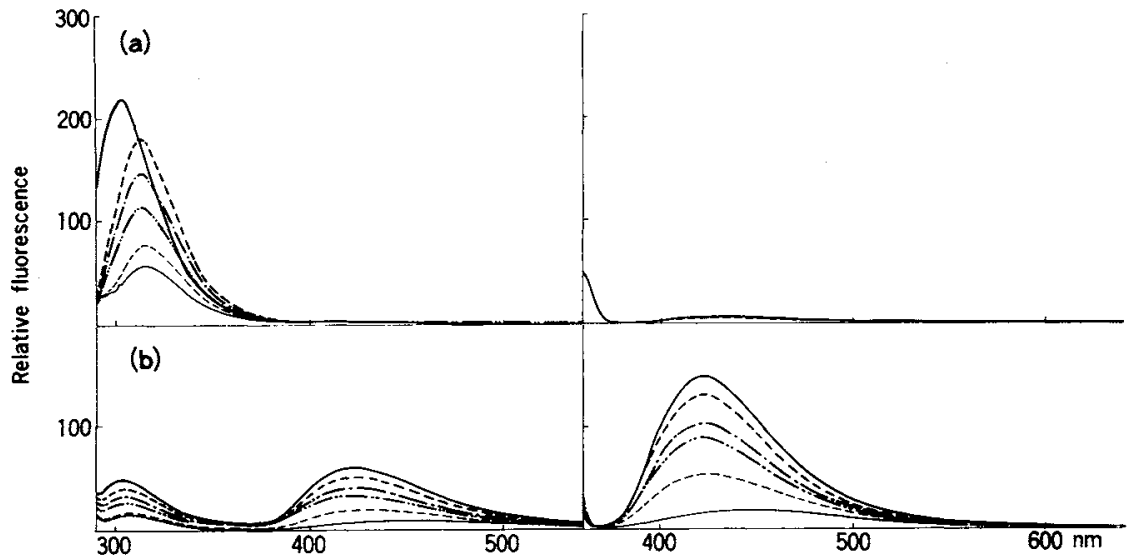

C-1027 and apoprotein $(0.5 \mathrm{mg} / \mathrm{ml})$ in $0.01 \mathrm{M}$ Tris- $\mathrm{HCl}$, pH 7.9 , were heated by $10^{\circ} \mathrm{C}$ increments to $80^{\circ} \mathrm{C}$.

spectra of the two proteins were significantly different. Fluorescence emission of C-1027 was observed at an excitation of both 280 and $350 \mathrm{~nm}$. It had an emission maximum at $304 \mathrm{~nm}$ by excitation at $280 \mathrm{~nm}$, which well corresponds to the absorption band of tyrosine residues in the protein moiety, and showed a second broad emission centered around $426 \mathrm{~nm}$ by excitation at $350 \mathrm{~nm}$. While, the apoprotein showed dramatically reduced emission at $426 \mathrm{~nm}$ and significantly higher emission at $304 \mathrm{~nm}$ than $\mathrm{C}-1027$ at $30^{\circ} \mathrm{C}$. At $304 \mathrm{~nm}$ the difference in fluorescence intensity between $\mathrm{C}-1027$ and apoprotein may be ascribed to fluorescence quenching related to the conformational change effected by binding of non-protein chromophore to protein moiety.

The excitation wavelengths of 280 and $350 \mathrm{~nm}$ were then used to examine each protein at 
different temperatures ranging in $10^{\circ} \mathrm{C}$ intervals from 30 to $80^{\circ} \mathrm{C}$. In the apoprotein spectrum, the intensity of fluorescence emission of tyrosyl residues decreased linearly as expected with increasing temperature, and the emission maximum at $304 \mathrm{~nm}$ shifted to $315 \mathrm{~nm}$ at more than $40^{\circ} \mathrm{C}$ after the thermal transition, whereas in $\mathrm{C}-1027$, the $426 \mathrm{~nm}$ emission maximum from excitation at $350 \mathrm{~nm}$ was essentially absent at the higher temperatures. No deviation from linearity occurred with respect to the change in fluorescence emission in C-1027 and apoprotein. It would appear that such an environmental change occurred at the tyrosine residues in apoprotein, leading to a shift in the emission maximum from 304 to $315 \mathrm{~nm}$. Since the emission maximum at $426 \mathrm{~nm}$ in $\mathrm{C}-1027$ appeared to correlate with the presence of the non-protein chromophore in this protein, the fluorescence spectra suggested that chromophore might have been modified after heating, seen also in the ultraviolet absorbance spectra in which the definite absorption shoulder between 340 and $360 \mathrm{~nm}$ in the native $\mathrm{C}-1027$ was shifted to a shorter wavelength with no definitive maximum by UV-irradiation, as reported previously ${ }^{25}$. These spectral findings might point not only to modification of the non-protein chromophore but also to dissociation of the chromophore from the apoprotein of $\mathrm{C}-1027$ following heating.

By using the fluorescence technique, we attempted to determine the interaction between C-1027 chr-II and apoprotein. The fluorescence of the mixture of apoprotein and chr-II was measured after the solution had been mixed well. When apoprotein was added to a phosphate buffer solution of the chromophore, the 426-nm fluorescence of the chromophore excited at $350 \mathrm{~nm}$ increased in relative intensity with increasing concentration of apoprotein, as shown in Fig. 11. The peak intensity increased almost 16-fold, and the emission band shifted about $20 \mathrm{~nm}$ in the apoprotein-nonprotein chromophore adduct formed with equimolar concentrations of the two components. The spectrum of $\mathrm{C}-1027$ was much more similar to that measured for the chr-II, which occupies a largely hydrophobic environment in the holo-antibiotic. The dissociation constant $(K d)$ of apoprotein for chromophore, which was obtained from the fluorescence curves by the method of KONDO et al., was $6.88 \times 10^{-5} \mathrm{M}$ under these conditions. In a study testing the interaction between apo-NCS and NCS chromophore by this technique, it was reported that apo-NCS quenched the 448-nm fluorescence of NCS-chromophore excited at $340 \mathrm{~nm}$ in a concentration-dependent manner and that the $K d$ of it was $7.0 \times 10^{-6} \mathrm{M}^{26)}$. This result may indicate that the chromophore-protein interaction in NCS is more intensive than that in C-1027.

Many antitumor protein antibiotics such as NCS, MCR, AUR, AXN, and LRG are known generally to comprise an acidic protein in combination with a basic chromophore, and a similar feature holds for 
C-1027. The protein component of NCS has no cytotoxic activity and it serves primarily as a carrier protecting the chromophore from decomposition ${ }^{27)}$. AXN and AUR have similar functions but with different specificity regarding the nature and activity of the chromophore. In fact, despite substantial differences concerning the structure and reactivity of the antibiotic moiety, the apoproteins of NCS, MCR, AUR and AXN are similar in size, 108-113 amino acids, and have about 45\% sequence similar ${ }^{28)}$. However, AUR-chromophore is a poor ligand for NCS-apoprotein ${ }^{29)}$, and MCR does not bind the NCS-chromophore

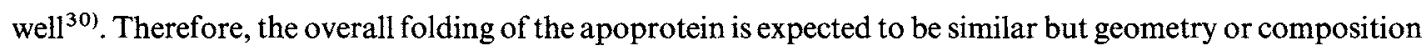
of the binding site should indicate differences that are related to the differences in the structures and activities of the chromophores. We reported earlier that holo-antibiotic $\mathrm{C}-1027$ had some aminopeptidase activity when tested with 1-phenylalanyl-4-methylcoumaryl-7-amide as the substrate, and neither its chromophore alone nor its apoprotein alone had this activity ${ }^{9}$. Amastatin and bestatin inhibited the enzyme activity. The cytotoxicity to Ehrlich carcinoma cells in vitro and aminopeptidase activity of C-1027 was reduced by UV-irradiation. The chromophore has been reported to be labile to UV-irradiation ${ }^{2,5)}$. Degradation of the chromophore by UV-irradiation should have resulted in changes of the native conformation of $\mathrm{C}-1027$ and loss of the catalytic activity. Thus, structure-activity correlation for the secondary and three-dimensional structure of the molecule should provide insight into its mode of action. However, the mode of apoprotein-chromophore interaction has not yet been clarified because the structure of apoprotein and of its chromophore has not been elucidated, except for NCS. Recently, based on detailed 2D-NMR studies and other spectral data, we found that the native chromophore obtained from isolated C-1027 consisted mainly of three structures, i.e., oxazolinate, a novel amino sugar, and a novel 9-membered endiyne core. Accordingly, we presume that chr-II, a stable C-1027 chromophore-derived reaction product, is formed by aromatization mechanism of the enediyne system of native chromophore. Therefore, the C-1027 chromophore is a member of the enediyne family of antibiotics as represented by NCS-chromophore, calichemicins, esperamicins, and dynemicin A. This novel class of extremely potent cytotoxic natural products has been characterized as having an enediyne conjugated chromophore by EDO et al. ${ }^{31)}$ and by researchers at the Lederle Laboratories ${ }^{32,33)}$ and Bristol-Myers ${ }^{34 \sim 37)}$, respectively. In addition to these, very recently, Bristol-Myers Squibb group has discovered a novel family of chromoprotein antitumor antibiotic, kedarcidin ${ }^{38)}$. The structure determination of kedarcidin consisting of an acidic apoprotein (114 amino acid residues) and the highly unstable chromophore possessing 9-membered ring endiyne core has been disclosed ${ }^{39,40)}$.

Recently, a significant $\beta$-strand character and lack of helices have been reported for NCS from the extensive analyses of proton NMR spectra ${ }^{41}$. The globular folding of the NCS molecule was also proposed from consideration of its structural similarity with $\mathrm{AXN}^{42)}$. We are currently attempting conformation analysis of C-1027 and apoprotein in solution by NMR-spectroscopy, together with crystallization of $\mathrm{C}-1027$ apoprotein for and preliminary $\mathrm{X}$-ray diffraction analysis, to obtain detailed structural information on the whole molecule. Because of both the homology in structure and function and the variation in chromophore structure and binding site composition, this family of protein antibiotics offers a unique opportunity for studies of structure-function relationships and chromophore-protein interactions. Particularly, detailed information about the chromophore-protein interactions should lead the way toward the development of improved antitumor agents.

\section{Acknowledgments}

The author would like to thank Professor M. HoRı of Showa College of Pharmaceutical Sciences for his valuable 
advice and encouragement during the course of this study. The author also wishes to thank Miss K. SAKAwA in our laboratory for the preparation of this manuscript.

\section{References}

1) Hu, J; Y.-C. Xue, M.-Y. XIE, R. Zhang, T. Otani, Y. Minami, Y. Yamada \& T. MaRunaka: A new macromolecular antitumor antibiotics, C-1027. I. Discovery, taxonomy of producing organism, fermentation and biological activity. J. Antibiotics 41: 1575 1579, 1988

2) Otani, T.; Y. Minami, T. Marunaka, R. Zhang \& M.-Y. XIE: A new macromolecular antitumor antibiotic, C-1027. II. isolation and physico-chemical properties. J. Antibiotics 41: 1580 1585, 1988

3) Otani, T.; T. Yasuhara, Y. Minami, T. Shimazu, R. Zhang \& M.-Y. Xie: Purification and primary structure of C-1027-AG, a selective antagonist of antitumor antibiotic C-1027, from Streptomyces globisporus. Agric. Biol. Chem. 55: 407 417, 1991

4) Sakata, N.; S. Ikeno, M. Hori, M. Hamada \& T. Otans: Cloning and nucleotide sequencing of the antitumor antibiotic C-1027 apoprotein gene. Biosci. Biotech. Biochem. 56: 1592 1595, 1992

5) OtANI, T.; Y. MINAMI, K. SAKAWA \& K. Yoshida: Isolation and characterization of non-protein chromophore and its degradation product from antibiotic C-1027. J. Antibiotics 44: 564 568, 1991

6) ZheN, Y.-S.; X.-Y. Ming, B. YU, T. OtANi, H. SaITo \& Y. YAMadA: A new macromolecular antitumor antibiotic, C-1027. III. Antitumor activity. J. Antibiotics 42: 1294 1298, 1989

7) Sugimoto, Y.; T. Otani, S. Oie, K. WierzaA \& Y. Yamada: Mechanism of action of a new macromolecular antitumor antibiotic, C-1027. J. Antibiotics 43: 417 421, 1990

8) XU, Y.-J.; D.-D. LI \& Y.-S. ZHEN: Mode of action of C-1027, a new macromolecular antitumor antibiotic with highly potent cytotoxicity, on human hepatoma BEL-7402 cells. Cancer Chemother. Phamacol. 27:41 46, 1990

9) Sakata, N.; K. S.-Tsuchiya, Y. Moriya, H. Hayashi, M. Hori, T. Otani, M. Nagai \& T. Aoyagi: Aminopeptidase activity of an antitumor antibiotic, C-1027. J. Antibiotics 45: $113 \sim 117,1992$

10) Ishida, N.; K. Mryazaki, K. Kumagai \& M. Rikimaru: Neocarzinostatin, an antitumor antibiotic of high molecular weight. Isolation, physicochemical properties and biological activities. J. Antibiotics, Ser. A 18: 68 76, 1965

11) Yamashita, T.; N. NaOl, T. Hidaka, K. Watanabe, Y. Kumada, T. Takeuchi \& H. Umezawa: Studies on auromomycin. J. Antibiotics 32: 330 339, 1979

12) Chimura, H.; M. Ishizuka, M. Hamada, S. Hori, K. Kimura, J. Iwanaga, T. Takeuchi \& H. UmeZawa: A new antibiotic, macromomycin, exhibiting antitumor and antimicrobial activity. J. Antibiotics $21: 44 \sim 49,1968$

13) Yamaguchi, T.; T. Furumai, M. Sato, T. OKuda \& N. Ishida: Studies on a new antitumor antibiotic, largomycin. I. Taxonomy of the largomycin-producing strain and production of the antibiotic. J. Antibiotics 23: $369 \sim 372,1970$

14) Khokhlov, A. S.; B. Z. Cherches, P. D. Reshetov, G. M. Smirnova, I. B. Sorokina, T. A. Prokoptzeva, T. A. Koloditskaya, V. V. Smirnov, S. M. Navashin \& I. P. Fomina Physico-chemical and biological studies on actinoxanthin, an antibiotic from Actinomyces globisporus 1131. J. Antibiotics 22: 541 544, 1969

15) Kondo, H.; H. NaKatani \& K. Hiromi: Interaction of cyclodextrins with fluorescent probes and its application to kinetic studies of amylase. J. Biochem. 79: 393 405, 1976

16) ChANG, C. T.; C.-S. C. WU \& J. T. YANG: Circular dichroic analysis of protein conformation: inclusion of the $\beta$-turns. Anal. Biochem. 91: 13 31, 1978

17) Mryazawa, T. \& E. R. BLour: The infrared spectra of polypeptides in various conformations: Amide I and II bands. J. Am. Chem. Soc. 83: 712 719, 1961

18) Maeda, H.; H. Shiraishi, S. OnOdera \& N. Ishida: Conformation of antibiotic protein, neocarzinostatin, studied by plane polarized infrared spectroscopy, circular dichroism and optical rotatory dispersion. Int. J. Pept. Protein Res. 5: 19 26, 1973

19) SAmy, T. S. A.; M. Atreyi, H. Hafda \& J. MeIenhofer: Selective tryptophan oxidation in the antitumor protein neocarzinostatin and effects on conformation and biological activity. Biochemistry 13: 1007 1014, 1974

20) Mrwa, N.: Conformations of protein moieties and chromophore-protein interactions in the antitumor antibiotics, macromomycin and auromomycin, characterized by IR and CD spectral analysis. J. Antibiotics $35: 1553 \sim 1560$, 1982

21) Sarver, R. W. \& W. C. KRUEGER: Protein secondary structure from fourier transform infrared spectroscopy: A data base analysis. Anal. Biochem. 194: $89 \sim 100,1991$

22) Chou, P. Y. \& G. D. FASMAN: Prediction of the secondary structure of proteins from their amino acid sequence. Adv. Enzymol. 47: 45 48, 1978

23) Kyte, J. \& R. F. Doolittle: A simple method for displaying the hydropathic character of a protein. J. Mol. Biol. 157: $105 \sim 132,1982$

24) Edo, K.; K. Saito, Y. Akiyama, M. Mizugaki, Y. KoIde \& N. Ishida: Neocarzinostatin: Carboxyl-terminal-43- 
peptide residue of apo-neocarzinostatin as the binding site of neocarzinostatin-chromophore. Chem. Pharm. Bull. 34: $5180 \sim 5183,1986$

25) Otani, T.; Y. Minami, T. Marunaka, R. Zhang \& M.-Y. XIE: C-1027-AG, a selective antagonist of the macromolecular antitumor antibiotic, C-1027. J. Antibiotics 41: 1696 1698, 1988

26) Edo, K.; K. Saito, Y. Akiyama-Murai, M. Mizugaki, Y. Kolde \& N. Ishida: An antitumor polypeptide antibiotic neocarzinostatin: The mode of apoprotein-chromophore interaction. J. Antibiotics 41: 554 562, 1988

27) KAPPEN, L. S.; M. A. NAPIER \& I. H. GolDBERG: Roles of chromophore and apo-protein in neocarzinostatin action. Proc. Natl. Acad. Sci. U.S.A. 77: 1970 1974, 1980

28) Samy, T. S. A.; K. S. Hahm, E. J. Modest, G. W. Lampman, H. T. Keutmann, H. Umezawa, W. C. Herlihy, B. W. Giason, S. A. Carr \& K. Biemann: Primary structure of macromomycin, an antitumor antibiotic protein. J. Biol. Chem. 258: 183 191, 1983

29) Kappen, L. S.; M. A. NAPIER, I. H. Goldberg \& T. S. A. SAMY: Requirement for reducing agents in deoxyribonucleic acid strand scission by the purified chromophore of auromomycin. Biochemistry 19: 4780 4785, 1980

30) KAPPEN, L. S. \& I. H. GOLDBERG: Stabilization of neocarzinostatin nonprotein chromophore activity by interaction with apoprotein and with HeLa cells. Biochemistry 19:4786 4790, 1980

31) Edo, K.; M. Mizugaki, Y. Koide, H. Seto, K. Furihata, N. Otake \& N. Ishida: The structure of neocarzinostatin chromophore possessing a novel bicyclo[7,3,0]dodecadiyne system. Tetrahedron Lett. 26: 331 334, 1985

32) Lee, M. D.; T. S. Dunne, M. M. Siegre, C. C. Chang, G. O. Morton \& D. B. Borders: Calichemicins, a novel family of antitumor antibiotics. 1. Chemistry and partial structure of calichemicin $\gamma_{1}{ }^{1}$. J. Am. Chem. Soc. 109: $3464 \sim 3466,1987$

33) Lee, M. D.; T. S. Dunne, C. C. Chang, G. A. Ellestad, M. M. Siegel, G. O. Morton, W. J. McGahren \& D. B. BORDERS: Calichemicins, a novel family of antitumor antibiotics. 2. Chemistry and structure of calichemicin $\gamma_{1}{ }^{\text {I }}$. J.:Am. Chem. Soc. 109: 3466 3468, 1987

34) Konishi, M.; H. Ohkuma, K. Saitoh, H. Kawaguchi, J. Golik, G. Dubay, G. Groenewold, B. Krishnan \& T. W. Doyle: Esperamicins, a novel class of potent antitumor antibiotics. I. Physico-chemical data and partial structure. J. Antibiotics 38: 1605 1609, 1985

35) Golik, J.; J. Clardy, G. Dubay, G. Groenewold, H. Kawaguchi, M. Konishi, B. Krishnan, H. Ohkuma, K. SAITOH \& T. W. DoYLE: Esperamicins, a novel class of potent antitumor antibiotics. 2. Structure of esperamicin X. J. Am. Chem. Soc. 109: $3461 \sim 3462,1987$

36) Golik, J.; G. Dubay, G. Groenewold, H. Kawaguchi, M. Kawaguchi, M. Konishi, B. Krishnan, H. OhKuma, K. SAITOH \& T. W. Doyle: Esperamicins, a novel class of potent antitumor antibiotics. 3. Structures of esperamicins $A_{1}, A_{2}$, and $A_{1 b}$. J. Am. Chem. Soc. 109: 3462 3464, 1987

37) Konishi, M.; H. Ohkuma, K. Matsumoto, T. Tsuno, H. Kamei, T. Miyaki, T. Oki, H. Kawaguchi, G. D. VANDUYNe \& J. ClaRdY: Dynemicin A, a novel antibiotic with the anthraquinone and 1,5-diyn-3-ene subunit. J. Antibiotics 42: $1449 \sim 1452,1989$

38) Hofstead, S. J.; J. A. Matson, A. R. Malacko \& H. Marquardt: Kedarcidin, a new chromoprotein antitumor antibiotic. II. Isolation, purification and physico-chemical properties. J. Antibiotics 45: 1250 1254, 1992

39) Leet, J. E.; D. R. Schroeder, S. J. Hofstead, J. Golik, K. L. Colson, S. Huang, S. E. Klohr, T. W. Doyle \& J. A. Matson: Kedarcidin, a new chromoprotein antitumor antibiotic: Structure elucidation of kedarcidin chromophore. J. Am. Chem. Soc. 114: 7946 7948, 1992

40) LeET, J. E.; J. Golik, S. J. Hofstead, J. A. Matson, A. Y. LeE \& J. Clardy: Kedarcidin chromophore: Structure elucidation of the amino sugar kedarosamine. Tetrahedron Lett. 33: 6107 6110, 1992

41) AdjadJ, E.; J. Mispelter, E. Quiniou, J.-L. Dimiculi, V. Favaudon \& J.-M. Lhoste: Proton NMR studies of apo-neocarzinostatin from Streptomyces carzinostaticus. Sequence-specific assignment and secondary structure. Eur. J. Biochem. 190: 263 271, 1990

42) PletneV, V. Z.; A. P. KuZin, S. D. Trakhanov \& P. V. Kostetsky: Three-dimensional structure of actinoxanthin. IV. A $2.5-\AA \AA$ resolution. Biopolymers 21: $287 \sim 300,1982$ 